\title{
Comparative Analysis of Pre and Post Re-basing Economic Performance of Nigeria Construction Sector for Economic Development
}

\author{
Peter Uchenna Okoye ${ }^{1, *}$, Peter Emenike Ogunoh ${ }^{1}$, Chinwendu Christopher Mbakwe ${ }^{2}$ \\ ${ }^{1}$ Department of Building, Nnamdi Azikiwe University, Nigeria \\ ${ }^{2}$ Department of Quantity Surveying, Nnamdi Azikiwe University, Nigeria
}

Copyright $\mathrm{O} 2016$ by authors, all rights reserved. Authors agree that this article remains permanently open access under the terms of the Creative Commons Attribution License 4.0 International License

\begin{abstract}
This study analysed pre and post re-basing economic performance of Nigeria construction sector with a view to ascertaining if significant improvements have been achieved in terms of construction output, construction growth rate, contribution to Gross Domestic Product (GDP) and economic development. Data were obtained from the publications of the Central Bank of Nigeria and the National Bureau of Statistics from 1981 to 2015, and analysed using Z test and Pearson correlation. Statistically, the study found that there was significant improvement in the construction sector outputs and contribution to GDP after re-basing as the computed $Z$ scores (-8.0381) and (-5.4647) were greater than the critical value (1.96) at $5 \%$ significance difference respectively. The correlation coefficients $(0.706)$ and $(0.561)$ and the p-values $(<0.00001)$ indicated a strong and significant correlations. However, there was no significant difference in the growth rate of construction sector and GDP after re-basing as the computed $\mathrm{Z}$ scores $(-0.2388)$ and $(0.2835)$ were less than the critical value (1.96). The correlation coefficient $(0.030)$ and $(0.036)$ and p-values $(0.81126)$ and $(0.776794)$ also showed a very weak and non-significant correlation. This implied that Nigeria economic re-basing has triggered improvement in construction output and contribution to GDP but not in construction growth rate and GDP growth rate as previously believed.
\end{abstract}

Keywords Construction Sector, Economic Development, GDP, Nigerian Economy, Performance Improvement, Re-basing

\section{Introduction}

The continuous process of development and innovations has led to structural changes whereby a number of new products appear in the market and at the same time many products disappear. Recent reports on Nigeria economy show that the economy has experienced great changes in terms of the volume of activities covered in all sectors. The demand side of the economy consumption and investment patterns also experience structural changes. All these factors make it necessary to re-base the National Accounts series periodically. Re-basing the National Accounts captures the structural changes in the economy and thus gives a more accurate description. Therefore, re-basing of Nigeria National Account has added another image to the Nigerian economy such that the country has become the largest economy in Africa.

The re-basing and re-benchmarking exercise of Nigeria's National Account Estimates (including the Gross Domestic Product, GDP series) was concluded by the National Bureau of Statistics (NBS) between April and July 2014. NBS [1] reports that the statistical exercise resulted in a revision of nominal and real GDP estimates as well as growth rates of GDP for the period 2010 to 2014, as the base year (i.e. the reference year for computation) was adjusted from 1990 to 2010. The selection of a base year was determined by the availability of data as well as the stability of the general economy during that year. Before the current re-basing project, Nigeria had not re-based since 1990, whereas the UN Statistical Commission recommends the exercise be carried out every 5 years. In addition, new guidelines released by relevant international statistical bodies necessitated that the National Bureau of Statistics also updates its computational frameworks [1].

A comparative analysis of Nigeria and other African countries reveals that Nigeria currently has one of the highest increases in nominal value of GDP in Africa, with an increase of about $89.22 \%$. South Africa's 2009 re-basing, which revised its base year from 2000 t0 2005 and had $2.1 \%$ increase in nominal GDP; Ghana's 2010 re-basing from 1993 to 2006 base year had $62.8 \%$ increase in 2006 GDP figure [2]. Consequently, Euromoney Institutional Investor Company (EMIS) reports that Nigeria alone generated 
one-fifth of African GDP as its share in Sub-Saharan African GDP as her GDP increased from 18\% in 2009 to around 32\% in 2013 and thus, outpaced the South African economy which used to be the largest economy, but whose share decreased from $30 \%$ in 2009 to $22 \%$ in 2013 [3]. The boom in the oil sector also played a key role for the economic development in Nigeria in the past but the current slump in oil prices caused serious problem for the Nigeria economy and presented a major risk for the construction industry. This has resulted to reduced budget revenues and restricted the government's abilities for infrastructure investment, thereby, leading to freezing of budget-funded projects and increased number of redundant people in the construction industry [3].

In terms of construction performance however, the construction industry has been adjourned to be one of the drivers of social and economic development of any nation [4-6]. The post re-basing data in the construction sector shows a much more optimistic picture, as more modern construction activities have been captured, and prices correctly deflated [7]. In view of this, Dlamini [8] argues that the construction industry has a potential of positive impact on economic growth and it's an important component in the investment programmes in developing economies. Roodman and Lennsen [9] observe that one-tenth of global economy is dedicated to constructing, operating and equipping buildings, and this activity accounts for $40 \%$ of the material flow entering the world economy, with much of the rest destined for roads, bridges and vehicles to connect the buildings. While Cochrane [5] notes that construction industry worldwide was predicted to have a total growth of $30 \%$ from 2010 to 2015, giving it an approximated total value of over $\$ 3,000$ billion (US) in 2015, Du Plessis [10] avers that it is the world's largest industrial employer (111 million employees) and in most countries it accounts for more than half of capital investment and as much as 10 per cent of GNP.

However, the current economic situation in Nigeria has call for critical economic thinking and decisions. While Egwuekwe [2] acknowledges GDP re-basing as a measure to achieve economic growth, she argues that Nigeria economic growth does not necessarily amount to economic development, as GDP does not measure inequality. Egwuekwe [2] further avers that Nigeria is saddled with a high rate of importation, severe poverty level, high level of unemployment, poor infrastructure, and high income inequality, despite remaining the biggest African nation in terms of GDP. Therefore, this period of economic quagmire coupled the dwindling economic fortunes, requires workable policies and decisive economic decisions based on accurate information in all sectors of the economy for efficient and sustainable economic growth.

Unfortunately, there is dearth of empirical research tracing and comparing the economic trends of real sectors of Nigeria economy especially the construction sector. The policy makers and economic planners have over the years based their projections on estimations and guesses and this has been a source of concern to the stakeholders. The fact that the growth rate of the construction industry in the developing countries is more than the GDP growth rate, and that the percentage it takes in the GDP of developed countries relatively diminishes [11] is a subject of further investigation. Few existing studies have only attempted to consider the relationships between the construction sector and the Nigerian economy [12-16]. Most of these studies used pre re-based data while only Okoye [15] used post re-based data to assess the contributions of construction sector to the economic development of Nigeria. None of these studies have actually compared the pre rebasing and post rebasing contributions of construction sector in Nigeria to ascertain if there is any difference in the economic performance of construction sector before and after re-basing exercise.

More importantly, construction sector is one of the sectors that have received significantly higher new estimates of their shares in GDP after re-basing the Nigerian national account [17], thus the need to assessing the performance of construction sector with respect to aggregate economy before and after re-basing exercise. It should be noted that this assessment and comparison would be used to make informed economic decisions as regard to the potentiality of construction sector to growing national economy. Based on the forgoing, this study argues that there are no significant differences between the pre rebasing and post rebasing economic performances of construction sector. In response to this, this study compares the pre re-basing and post re-basing economic performances of construction sector to determine if the sector has improved substantially in terms of economic advancement and development of Nigeria.

The study then adduces the following hypotheses to guide the investigation:

1. There is no significant difference between the construction sector output before and after re-basing of Nigeria national accounts.

2. There is no significant difference between the construction sector growth rate before and after re-basing of Nigeria national accounts.

3. There is no significant difference between the construction sector contribution to GDP before and after re-basing of Nigeria national accounts.

4. There is no significant difference in the Nigerian economic growth before and after re-basing.

\section{Methodology}

The annual statistical data from 1981 to 2012 (for pre re-basing period) and 1981 to 2015 (for post re-basing period) on construction sector output, growth in construction sector, total Gross Domestic Product and GDP growth were extracted from the Central Bank of Nigeria $(\mathrm{CBN})$ and National Bureau of Statistics (NBS) publications in Million Naira and employed to analyse the performance of construction sector for these periods. Tables 1 and 2 present the annual total real GDP, GDP growth, total construction sector output, construction sector growth and construction 
sector percentage contribution to GDP at 1990 and 2010 constant basic prices respectively. Annual observations of GDP and construction sector data were extracted from the following CBN and NBS publications: CBN Statistical Bulletin 2009 [18], Revised 2010 and Estimates for Q1-Q4, 2011 Gross Domestic Product for Nigeria [19], Revised 2011 and Estimates for Q1-Q4, 2012 Gross Domestic Product for Nigeria [20],Revised and Final GDP Rebasing Results by Output Approach [21], Nigerian Construction Sector Summary Report 2010-2012 [7], Nigerian Gross Domestic Product Quarterly Report, Quarter Four 2014 [22], Nigerian Gross Domestic Product Quarterly Report, Quarter Four 2015 [23], and Post GDP Rebasing Revision: 1981-2010 [24].

The comparative analysis of construction sector performance for this study is based on the sectors output, annual growth rate and contribution to the GDP. Descriptively, pre-rebased and post-rebased performance of construction sector is compared using graphs and charts. To determine if there is significant difference between the pre-rebasing and post-rebasing performance of Nigeria construction sector, the mean outputs, growths and contribution to GDP of the two sample groups were compared using standard normal score ( $\mathrm{Z}$ score) test statistics, since the sample size for each the study is greater than 30. Thus, test statistic is given as:

$$
\mathrm{z}=\frac{\overline{\mathrm{X}}_{1}-\overline{\mathrm{X}}_{2}}{\sqrt{\frac{\sigma_{1}^{2}}{\mathrm{n}_{1}}+\frac{\sigma_{2}^{2}}{\mathrm{n}_{2}}}}=\frac{\overline{\mathrm{X}}_{1}-\overline{\mathrm{X}}_{2}}{\sqrt{\sigma_{p}^{2}\left[\frac{1}{\mathrm{n}_{1}}+\frac{1}{\mathrm{n}_{2}}\right]}}
$$

Where $\bar{X}_{1}$ and $\bar{X}_{2}$ are sample means for pre-rebasing and post-rebasing outputs respectively; $\sigma^{2}{ }_{1}$ and $\sigma^{2}{ }_{2}$ are sample variances; $\mathrm{n}_{1}$ and $\mathrm{n}_{2}$ are sample sizes, and

$$
\sigma_{\mathrm{p}}^{2}=\frac{\left(\mathrm{n}_{1}-1\right) \sigma_{1}^{2}+\left(\mathrm{n}_{2}-1\right) \sigma_{2}^{2}}{\mathrm{n}_{1}+\mathrm{n}_{2}-2}
$$

Degree of freedom $(\mathrm{df})=\mathrm{n}_{1}+\mathrm{n}_{2}-2$

$$
\begin{aligned}
\sigma_{\mathrm{i}}^{2} & =\frac{\sum\left(x_{i}-\bar{x}\right)^{2}}{\mathrm{n}} \\
S D & =\sqrt{\sigma_{\mathrm{i}}^{2}} \\
\overline{\mathrm{X}} & =\frac{\sum x_{i}}{\mathrm{n}}
\end{aligned}
$$

Thus, let the pre-rebasing output, growth and contribution be $X_{1}$, and the post-rebasing output, growth and contribution be $\mathrm{X}_{2}$. Also let the variances of the pre-rebasing output, growth and contribution be $\sigma^{2}{ }_{1}$ and the post-rebasing output, growth and contribution be $\sigma_{2}^{2}$. At the same time, the standard deviation (SD) for pre and post rebasing variables are equally computed using equation (5).
Decision: Reject $\mathrm{H}_{0}$ if $\mathrm{Z}$ score is greater than $\mathrm{Z}$-tabulated at $5 \%$ significance difference $\left(\mathrm{Z}_{1-\alpha / 2}\right)$; otherwise accept $\mathrm{H}_{0}$.

However, it is not enough determining the significance difference of the group means using only simple test statistics, there is need to establish significance of variability of the differences by measuring the effect size. An effect size is simply an objective and standardised measure of the magnitude of observed effect [25]. In this case, the strength of the differences between the means was determined using Pearson Correlation Coefficient (r). Pearson Correlation Coefficient ( $\mathbf{r}$ ) expresses the relationship between the groups and the outcome variable. Pearson Correlation Coefficient (r) can be easily obtained from common test statistics. Therefore, $\mathbf{r}$ is a function of the observed $\mathrm{Z}$-score and the degree of freedom on which it is based [25]. Pearson Correlation Coefficient ( $\mathbf{r}$ ) is given as:

$$
r=\sqrt{z^{2}}
$$

Where $\mathrm{r}$ is correlation coefficient, $\mathrm{Z}$ is $\mathrm{Z}$-score and $\mathrm{df}$ is degree of freedom. The value of $r$ ranges from 0 to 1 , where 0 means there is no effect and 1 represents a perfect effect.

Decision: Reject $\mathrm{H}_{0}$ if $\mathrm{p}$-value is less than $0.05(\mathrm{p}<0.05)$ at $5 \%$ significance difference and degree of freedom of 65 ; otherwise accept $\mathrm{H}_{0}$.

\section{Results}

\subsection{Descriptive Analysis}

Tables 1 and 2 show the extracts of construction sector data and GDP before and after re-basing from various reports of CBN and NBS. The data on these tables would form the basis for comparisons. The tables show that the maximum construction outputs before and after re-basing are $\$ 19,505.62$ million in 2012 and $\$ 2,680,216.0$ million in 2015 respectively, while the minimum outputs are $\$ 3,308$ million in 1985 and $\$ 335,758.58$ million in 1986 respectively. The average construction outputs for the period were $\$ 7,515.94$ million and $\$ 923,337.3$ million respectively. The sector recorded the highest growth of $13.07 \%$ in 2008 for pre re-basing and $15.71 \%$ in 2011 for post re-basing. The minimum growth rate of $-31.11 \%$ was also recorded in both cases. The average growth rates for the period were $3.38 \%$ and $4.03 \%$ respectively. In terms of contribution to the overall GDP, the maximum contribution of the sector was $4.08 \%$ in 1981 and $5.58 \%$ also in 1981 respectively, while the minimum contribution was $1.44 \%$ in 2004 and $2.20 \%$ in 1986 respectively. The average construction contributions to GDP for the period were $2.02 \%$ and $2.91 \%$ respectively. 
Nigeria Construction Sector for Economic Development

Table 1. Annual Real GDP and Construction Sector Data at 1990 constant basic price (year-on-year)

\begin{tabular}{|c|c|c|c|c|c|}
\hline \multirow{2}{*}{ Observation } & \multicolumn{2}{|l|}{ GDP } & \multicolumn{3}{|c|}{ CONSTRUCTION } \\
\hline & Total GDP (N' Million) & Growth (\%) & Total Output (A' Million) & \% Contribution to GDP & Growth (\%) \\
\hline 1981 & $205,222.1$ & - & $8,377.0$ & 4.08 & - \\
\hline 1982 & $199,685.3$ & -2.70 & $6,681.5$ & 3.35 & -20.24 \\
\hline 1983 & $185,598.1$ & -7.05 & $5,890.4$ & 3.17 & -11.84 \\
\hline 1984 & $183,563.0$ & -1.10 & $4,802.0$ & 2.62 & -18.48 \\
\hline 1985 & $201,036.3$ & 9.52 & $3,308.0$ & 1.65 & -31.11 \\
\hline 1986 & $205,971.4$ & 2.45 & $3,302.9$ & 1.60 & -0.15 \\
\hline 1987 & $204,806.5$ & -0.57 & $3,610.3$ & 1.76 & 9.31 \\
\hline 1988 & $219,875.6$ & 7.36 & $3,978.1$ & 1.81 & 10.19 \\
\hline 1989 & $236,729.6$ & 7.67 & $4,143.6$ & 1.75 & 4.16 \\
\hline 1990 & $267,550.0$ & 13.02 & $4,350.8$ & 1.63 & 5.00 \\
\hline 1991 & $265,379.1$ & -0.81 & $4,524.8$ & 1.71 & 4.00 \\
\hline 1992 & $271,365.5$ & 2.26 & $4,701.3$ & 1.73 & 3.90 \\
\hline 1993 & $274,833.3$ & 1.28 & $4,936.3$ & 1.80 & 5.00 \\
\hline 1994 & $275,450.6$ & 0.22 & $5,084.4$ & 1.85 & 3.00 \\
\hline 1995 & $281,407.4$ & 2.16 & $5,221.7$ & 1.86 & 2.70 \\
\hline 1996 & $293,745.4$ & 4.38 & $5,284.3$ & 1.80 & 1.20 \\
\hline 1997 & $302,022.5$ & 2.82 & $5,622.5$ & 1.86 & 6.40 \\
\hline 1998 & $310,890.1$ & 2.93 & $5,959.9$ & 1.92 & 6.00 \\
\hline 1999 & $312,183.5$ & 0.42 & $6,186.4$ & 1.98 & 3.80 \\
\hline 2000 & $329,178.7$ & 5.44 & $6,433.8$ & 1.95 & 4.00 \\
\hline 2001 & $356,994.3$ & 8.45 & $7,205.9$ & 2.02 & 12.00 \\
\hline 2002 & $433,203.5$ & 21.35 & $7,518.9$ & 1.74 & 4.34 \\
\hline 2003 & $477,533.0$ & 10.16 & $8,176.8$ & 1.71 & 8.75 \\
\hline 2004 & $527,576.0$ & 10.46 & $7,622.5$ & 1.44 & -6.78 \\
\hline 2005 & $561,931.4$ & 6.51 & $8,544.5$ & 2.52 & 12.10 \\
\hline 2006 & $595,821.6$ & 6.03 & $9,654.8$ & 1.62 & 12.99 \\
\hline 2007 & $634,251.1$ & 6.45 & $10,912.6$ & 1.72 & 13.03 \\
\hline 2008 & $672,202.6$ & 5.98 & $12,338.8$ & 1.84 & 13.07 \\
\hline 2009 & $716,949.7$ & 6.66 & $13,851.1$ & 1.93 & 12.26 \\
\hline 2010 & $776,332.21$ & 8.28 & $15,454.02$ & 1.99 & 11.57 \\
\hline 2011 & $834,000.83$ & 7.43 & $17,325.58$ & 2.08 & 12.11 \\
\hline 2012 & $888,893.00$ & 6.58 & $19,504.62$ & 2.19 & 12.57 \\
\hline
\end{tabular}

Authors' Extracts from Various CBN and NBS Reports.

*Note: The construction growth rate and the GDP growth rate were computed on year-on-year basis 
Table 2. Annual Real GDP and construction sector data at 2010 constant basic price year-on-year

\begin{tabular}{|c|c|c|c|c|c|}
\hline \multirow{2}{*}{ Observation } & \multicolumn{2}{|l|}{ GDP } & \multicolumn{3}{|c|}{ CONSTRUCTION } \\
\hline & Total GDP (N' Million) & Growth (\%) & Total Output (N' Million) & \% Contribution to GDP & Growth (\%) \\
\hline 1981 & $15,258,004.34$ & - & $851,561.61$ & 5.58 & - \\
\hline 1982 & $14,985,078.32$ & -1.79 & $679,200.42$ & 4.53 & -20.24 \\
\hline 1983 & $13,849,725.17$ & -7.58 & $598,782.27$ & 4.32 & -11.84 \\
\hline 1984 & $13,779,255.49$ & -0.51 & $488,143.29$ & 3.54 & -18.48 \\
\hline 1985 & $14,953,913.05$ & 8.52 & $336,270.79$ & 2.25 & -31.11 \\
\hline 1986 & $15,237,987.29$ & 1.90 & $335,758.58$ & 2.20 & -0.15 \\
\hline 1987 & $15,263,929.11$ & 0.17 & $367,003.84$ & 2.40 & 9.31 \\
\hline 1988 & $16,215,370.93$ & 6.23 & $404,395.72$ & 2.49 & 10.19 \\
\hline 1989 & $17,294,675.94$ & 6.66 & $421,214.38$ & 2.44 & 4.16 \\
\hline 1990 & $19,305,633.16$ & 11.63 & $442,274.21$ & 2.29 & 5.00 \\
\hline 1991 & $19,199,060.32$ & -0.55 & $459,966.20$ & 2.40 & 4.00 \\
\hline 1992 & $19,620,190.34$ & 2.19 & $477,904.06$ & 2.44 & 3.90 \\
\hline 1993 & $19,927,993.25$ & 1.57 & $501,799.00$ & 2.52 & 5.00 \\
\hline 1994 & $19,979,123.44$ & 0.26 & $516,853.08$ & 2.59 & 3.00 \\
\hline 1995 & $20,353,202.25$ & 1.87 & $530,808.44$ & 2.61 & 2.70 \\
\hline 1996 & $21,177,920.91$ & 4.05 & $537,177.87$ & 2.53 & 1.20 \\
\hline 1997 & $21,789,097.84$ & 2.89 & $571,557.91$ & 2.62 & 6.40 \\
\hline 1998 & $22,332,866.90$ & 2.50 & $605,850.87$ & 2.71 & 6.00 \\
\hline 1999 & $22,449,409.72$ & 0.52 & $628,872.48$ & 2.80 & 3.80 \\
\hline 2000 & $23,688,280.33$ & 5.52 & $654,027.49$ & 2.76 & 4.00 \\
\hline 2001 & $25,267,542.02$ & 6.67 & $732,511.60$ & 2.90 & 12.00 \\
\hline 2002 & $28,957,710.24$ & 14.60 & $764,328.51$ & 2.64 & 4.34 \\
\hline 2003 & $31,709,447.39$ & 9.50 & $831,207.14$ & 2.62 & 8.75 \\
\hline 2004 & $35,020,549.08$ & 10.44 & $774,859.94$ & 2.21 & -6.78 \\
\hline 2005 & $37,474,949.16$ & 7.01 & $868,587.00$ & 2.32 & 12.10 \\
\hline 2006 & $39,995,504.55$ & 6.73 & $981,454.90$ & 2.45 & 12.99 \\
\hline 2007 & $42,922,407.93$ & 7.32 & $1,109,313.11$ & 2.58 & 13.03 \\
\hline 2008 & $46,012,515.31$ & 7.20 & $1,254,300.33$ & 2.73 & 13.07 \\
\hline 2009 & $49,856,099.08$ & 8.35 & $1,404,496.02$ & 2.82 & 11.97 \\
\hline 2010 & $54,612,264.18$ & 9.54 & $1,570,973.47$ & 2.88 & 11.85 \\
\hline 2011 & $57,511,041.77$ & 5.31 & $1,905,574.90$ & 3.31 & 15.71 \\
\hline 2012 & $59,929,893.04$ & 4.21 & $2,188,718.59$ & 3.05 & 9.44 \\
\hline 2013 & $63,218,721.73$ & 5.49 & $2,272,376.69$ & 3.59 & 14.22 \\
\hline 2014 & $67,157,384.39$ & 6.23 & $2,568,464.75$ & 3.82 & 13.03 \\
\hline 2015 & $69,023,929.95$ & 2.78 & $2,680,216.00$ & 3.88 & 4.35 \\
\hline
\end{tabular}

Authors' Extracts from Various NBS Reports.

*Note: The construction growth rate and the GDP growth rate were computed on year-on-year basis 


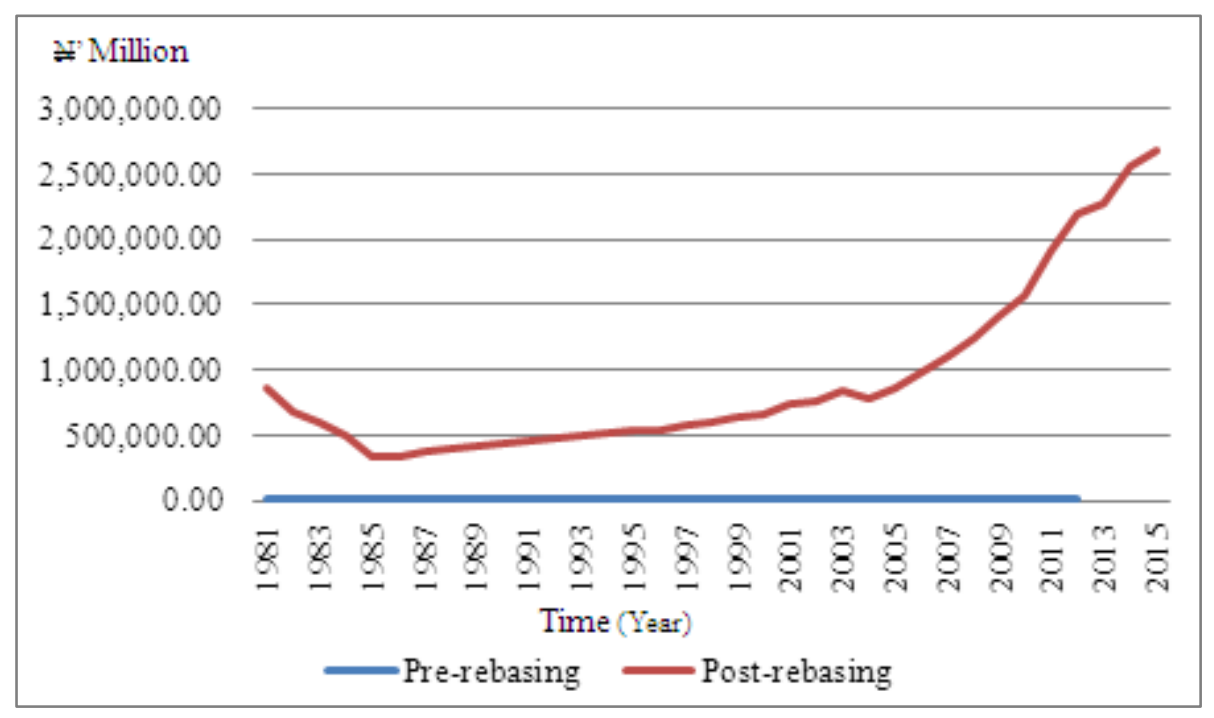

Figure 1. Construction sector output before and after re-basing

Figure 1 shows that construction sector output after re-basing far outpaced that before re-basing in term of volume. However, there was a steady decrease in the amount of construction output from 1981 to 1986 before it returned to increasing trend which it sustained from $1987-2003$ in both cases. In 2004, there was a drop in the construction output but by 2005, the output steadily and by margin till the end of the period under consideration in both cases.

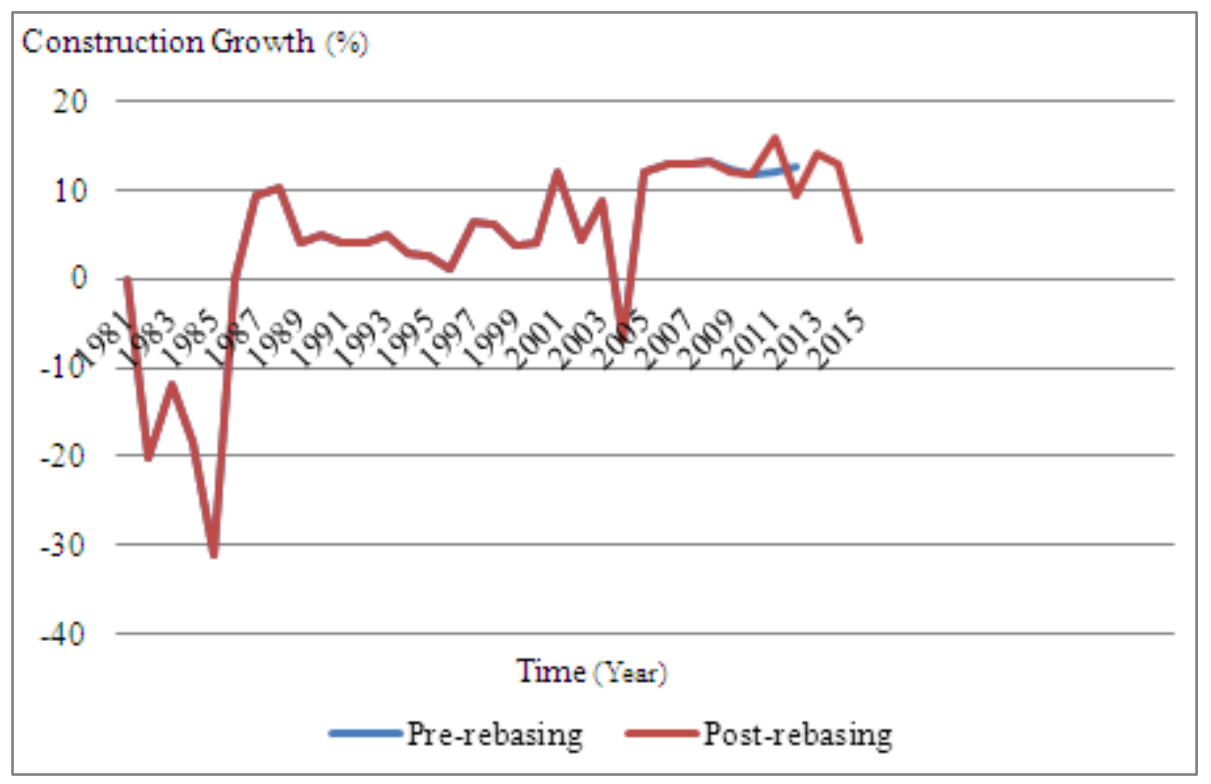

Figure 2. Construction sector growth rate before and after re-basing

Figure 2 shows that the growth rate of construction sector before and after re-basing was the same from 1981 to 2008 and began to vary from 2009. There was a fluctuation in the growth rate of construction sector in the period under consideration. In 1985 , sector grew minimally at $-31.11 \%$ in both cases, and grew maximally at $13.07 \%$ in 2008 and at $15.71 \%$ in 2011 before and after re-basing respectively. Of very important to note is that the sector maintained a negative growth rate from 1982 to 1986 and only returned to negative growth in 2004 in both cases. Unlike the general belief that the construction sector plays a crucial role in Nigeria's economic growth, construction industry is not a driver of GDP growth but a follower of fluctuations in the macro-economy. 


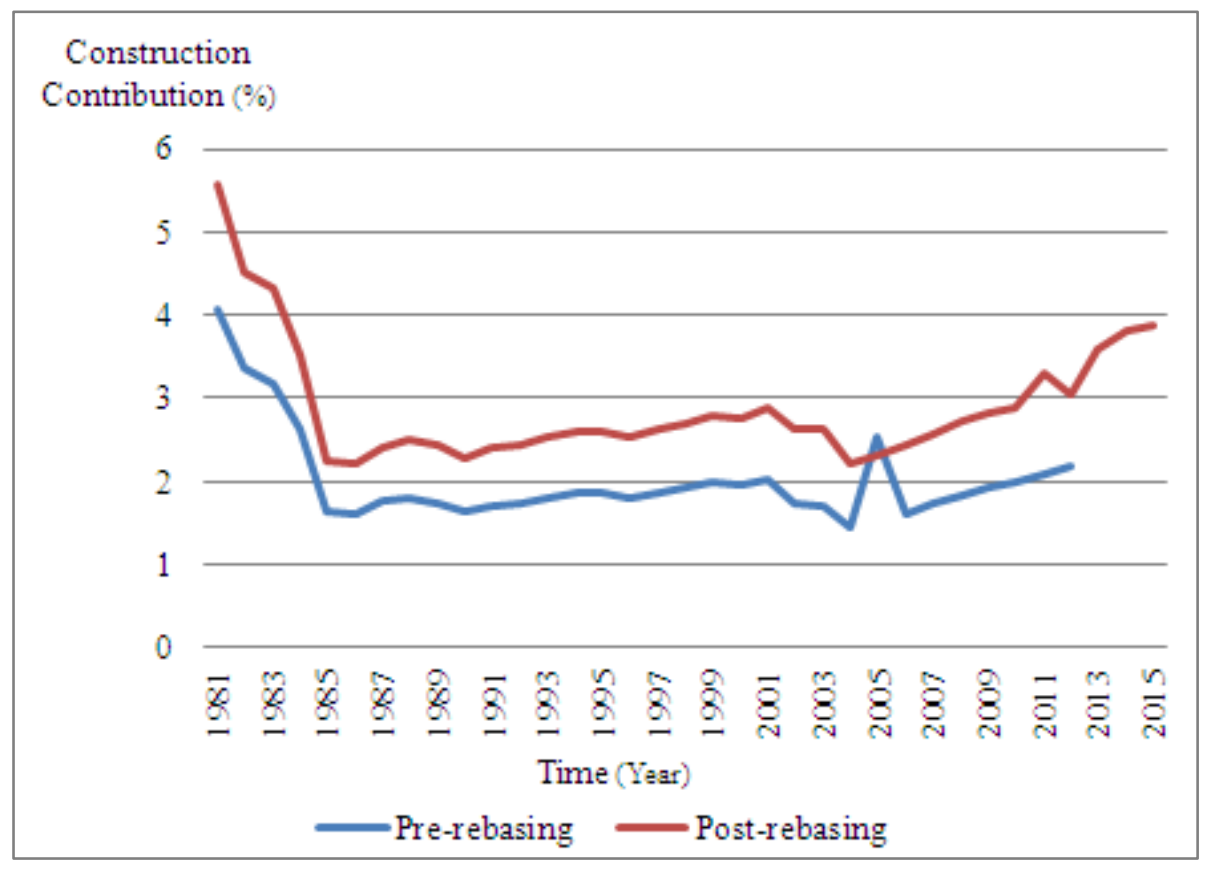

Figure 3. Construction sector contribution to GDP before and after re-basing

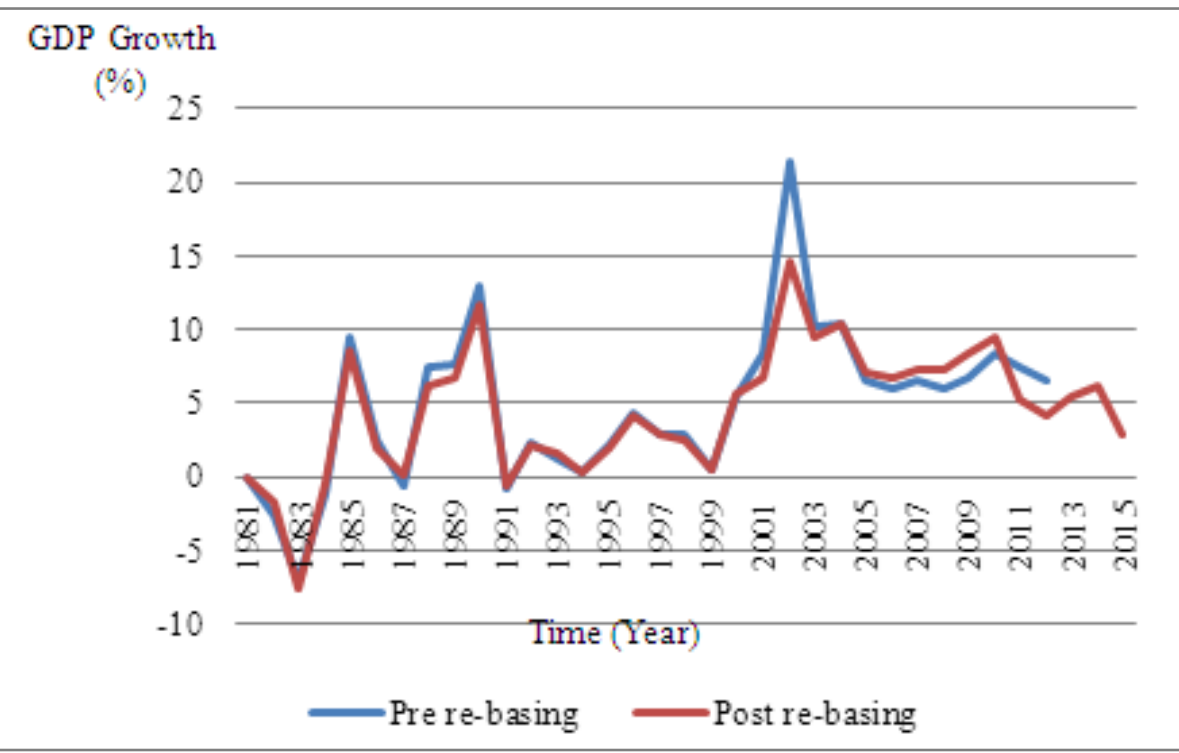

Figure 4. GDP growth rate before and after re-basing

In terms of contribution to the GDP, figure 3 showed that the construction sector contribution before re-basing was greatest at $4.08 \%$ in 1981 and least at $1.44 \%$ in 2004 . From 1985, the construction sector contribution to GDP before re-basing remained below 2\% except in 2001, 2005, 2011 and 2012 when it contributed just very little above 2\%. The post re-basing contribution of construction sector to GDP shows that the sector maximum contribution was 5.58\% in 1981 and the minimum contribution was $2.20 \%$ in 1986 . The construction contribution decreased steadily from $5.58 \%$ in 1981 to $2.20 \%$ in 1986 and remained below 3\% till 2011 when its contribution improved to above 3\% till 2015.

Figure 4 showed that the pre and post re-based GDP growth rate was greatest in 2002 and at $21.35 \%$ and $14.60 \%$ respectively. The lowest growth was recorded in 1983 with -7.05 for pre re-basing and deeper $-7.58 \%$ for post re-basing. It further revealed that there was not much improvement in the GDP growth rate rather slight decrease was observed in some years. 
Table 3. Result of z-test and Pearson correlation between the pre re-basing and post re-basing economic performance of construction sector

\begin{tabular}{|c|c|c|c|c|c|c|c|c|c|c|}
\hline \multirow{2}{*}{$\begin{array}{l}\mathrm{S} / \\
\mathrm{N}\end{array}$} & \multirow[b]{2}{*}{ Test } & \multicolumn{2}{|c|}{ Variance } & \multicolumn{2}{|c|}{ Standard Deviation } & \multirow[b]{2}{*}{ Z-score } & \multirow[b]{2}{*}{$\left(Z_{1-\alpha / 2}\right)$} & \multirow{2}{*}{$\begin{array}{l}\text { Corr. } \\
\text { coeff. } \\
(\mathrm{r})\end{array}$} & \multirow[b]{2}{*}{ P-value } & \multirow[b]{2}{*}{ Decision } \\
\hline & & $\begin{array}{c}\text { Pre } \\
\text { re-basing }\end{array}$ & $\begin{array}{c}\text { Post } \\
\text { re-basing }\end{array}$ & $\begin{array}{c}\text { Pre } \\
\text { re-basing }\end{array}$ & $\begin{array}{c}\text { Post } \\
\text { re-basing }\end{array}$ & & & & & \\
\hline 1 & $\begin{array}{l}\text { Construction } \\
\text { sector output }\end{array}$ & $1.63 \times 10^{7}$ & $4.15 \times 10^{11}$ & 4037.33 & 644204.94 & -8.0381 & 1.96 & 0.706 & $<0.00001 *$ & Reject $\mathrm{H}_{0}$ \\
\hline 2 & $\begin{array}{l}\text { Construction } \\
\text { sector growth } \\
\text { rate }\end{array}$ & 111.248 & 108.051 & 10.55 & 10.39 & -0.2388 & 1.96 & 0.030 & 0.81126 & Accept $\mathrm{H}_{0}$ \\
\hline 3 & $\begin{array}{l}\text { Construction } \\
\text { sector } \\
\text { contribution to } \\
\text { GDP }\end{array}$ & 0.3064 & 0.5433 & 0.55 & 0.74 & -5.4647 & 1.96 & 0.561 & $<0.00001 *$ & Reject $\mathrm{H}_{0}$ \\
\hline 4 & $\begin{array}{l}\text { GDP growth } \\
\text { rate }\end{array}$ & 27.6529 & 18.8113 & 5.26 & 4.34 & 0.2835 & 1.96 & 0.036 & 0.776794 & Accept $\mathrm{H}_{0}$ \\
\hline
\end{tabular}

Note: * indicates significant at $5 \%$ significance difference

\subsection{Test of Hypotheses}

Table 3 showed the results of computed Z-test and Pearson correlation between the pre re-basing and post re-basing economic performance of construction sector. The result revealed that the computed Z-score (8.0381) for the construction sector output was greater than the tabulated $\mathrm{Z}$ value (1.96) in absolute term. The result of Pearson correlation (0.706) showed that there was strong correlation between the construction output before and after re-basing. A further analysis revealed that there was significant difference between the construction sector output before and after re-basing exercise which lead to rejection of $\mathrm{H}_{0}$. This is affirmed by the p-value $(<0.00001)$ which indicated that it was less than 0.05 . Likewise, the result revealed that the computed Z score (5.4647) for construction sector contribution to GDP was greater than the tabulated $\mathrm{Z}$ score (1.96) at $5 \%$ significance difference in absolute term. The Pearson correlation coefficient $(0.561)$ indicated a moderate effect. The result further revealed that there was significant difference between the pre rebasing and post re-basing contribution of construction sector to GDP. This was also confirmed by the p-value $(<0.00001)$ which was less than 0.05 . In this case also, $\mathrm{H}_{0}$ was rejected.

However, the result showed that the computed $\mathrm{Z}$ scores for the construction sector growth rate $(0.2388)$ and GDP growth rate $(0.2835)$ were less than the critical value (1.96). The Pearson correlation coefficients (0.030and 0.036) indicated a very weak effect between the pre and post re-basing growth rate in both construction and GDP respectively. In this case, there was no significant difference between the pre re-basing growth rate and post re-basing growth rate of construction sector and GDP. This was further affirmed by the p-values ( 0.81126 and 0.776794$)$ which were greater than 0.05 . Overall, the result is supported by the results of the variance and standard deviation.

\section{Discussion}

The result of this study implied that after re-basing of Nigeria national accounts, the construction sector output improved significantly so also its contribution to the real GDP. However, this was not the case in terms of construction sector growth rate and GDP growth rate in that there was no significant change in the growth rate of the construction sector after re-basing. The result further implied that more items were included in the construction sector estimates during re-based which have helped to improve the output and contribution to GDP. Unfortunately, the improvement in the output and contribution to GDP did not translate to construction growth, GDP growth and economic development which suggested that the real economic improvement of construction sector has not been achieved through re-basing. This result was supported by [26] who found that construction is not a major driver of GDP rather a follower of macroeconomic fluctuations. Overall, this result was substantiated and suggested by the values of variances and standard deviations of the pre and post re-based construction outputs, construction growth rate and contribution to GDP; and the percentage differences between the mean values of each variable. The extent of the differences can equally be observed from figures (1- 4).

Generally, the result implied that the re-basing exercise has not improved economic developments to ensure sustainability and it is in tandem with the findings of [2], even though the GDP re-basing has firmed up Nigeria's position as an emerging market economy. To drive home this point, the level of poverty and unemployment still pervading the spheres of Nigeria attested that re-basing has not substantially improve construction growth and by extension, the economic development. Conversely, Kwanga [27] has justified this phenomenon and stated that growth occasioned by re-basing cannot be automatically transformed into economic development due to certain exigencies. This has also been supported by the Okun's Law $[28,29]$.

\section{Conclusions}

The fact that construction sector is one of the sectors that have received significantly higher new estimates of their shares in GDP after re-basing the Nigerian National Account 
requires statistical investigation so as to compare if significant improvement has been achieved in terms of construction output, construction growth and construction contribution to GDP. Thus, this study has compared the performance of construction sector in terms of output, growth, and contribution before and after re-basing exercise. The study found that there was significant difference in the construction sector output and contribution to GDP before and after re-basing. This implied that the output and contribution of construction sector to GDP have significantly improved from what they used to be before re-basing.

However, the study also revealed that there was no significant difference in the construction sector growth rate and GDP growth before and after re-basing. This meant that there has not been any significant improvement in the growth rate of construction sector and GDP after re-basing exercise. This could also be implied that the general belief that the construction sector plays a crucial role in Nigeria's economic growth does not hold, thus, construction industry is not a major driver of GDP growth but a follower of fluctuations in the macro-economy. This could also imply that the much hyped re-basing exercise did not substantially improved Nigeria economic growth and development, despite adding more items in the national account estimates.

It could be seen that this study is very germane in the sense that it would engender further evaluation and re-examination of GDP estimates especially as it concerns the construction sector. This study has disputed the age long belief that construction sector held a pivotal role in the growth and economic development of many nations. Of very important is the significance of this study to economic planners, policy makers, construction investors and government agencies. The result of this study is a guide for economic planning and investment decision. It would help the government in areas of intervention programme and capacity building. Particularly, the result has called for deeper thinking in making the construction sector more viable for economic growth and development especially in the developing countries like Nigeria.

The uniqueness of this study is phenomenal in the sense that no known study has actually compared the performance of construction sector based on its output, growth rate and contribution to GDP after the re-basing of Nigeria National Account. Thus, the study has added to the growing body of knowledge and will serve as a reference material for further research in this area. Based on the result of this study, it is recommended that the nation's economic planners should re-appraise what constitute the estimates of construction sector in the GDP for better articulation, deflation and inclusion so as to improve the economic performance of construction sector and the overall Nigeria economy especially in this period of economic turmoil. In view of the current state of the Nigerian economy, there is obvious need to stabilize the economy and improve the investment and development of both existing and new sectors of the economy. There is also need to build capacities around the construction sector's sub-sectors so as to maximise its potentials in repositioning and rescuing the dwindling economy.

\section{REFERENCES}

[1] National Bureau of Statistics (NBS). A Note on GDP Rebasing / Re-Benchmarking Exercise and the Comparability of GDP Growth Rates (Pre and Post Rebasing), 2014a. Online available from www.nigeranstat.gov.ng.

[2] F. Egwuekwe. How Sustainable is the Effect of Nigeria's GDP Re-basing? Aluko \& Oyebode, 2015. Online available from www.aluko-oyebode.com.

[3] EMIS. Construction Sector Sub-Saharan Africa, EMIS Insight, A Euromoney Institutional Investor Company, 2015.

[4] A. Stawińska. The EU-27 Construction Sector: From Boom to Gloom, Industry, Trade and Services, Eurostat Statistics in Focus, Vol. 7, 2010. Online available from http://ec.europa.eu/eurostat.

[5] J. Cochrane. Growth of Construction in India: Great Expectations for the Construction Industry in India. Thought Leadership, 2013.

[6] C. Rhodes. The Construction Industry: Statistics and Policy, Economic Policy and Statistics, House of Common Library, 2014.

[7] National Bureau of Statistics (NBS). Nigerian Construction Sector Summary Report: 2010-2012, 2015a. Online available from www.nigeranstat.gov.ng.

[8] S. Dlamini. Relationship of Construction Sector to Economic Growth. CIB Paper 2012, International Congress on Construction Management, Canada, 2012.

[9] M. D. Roodman, N. Lennsen. Our Buildings, Ourselves, World Watch, Vol. 7, No. 6, pp. 21-29, 1994.

[10] C. Du Plessis. Agenda 21 for Sustainable Construction in Developing Countries, A Discussion Document, Report for the CIB and UNEP-IETC, CSIR Building Construction and Technology, Pretoria, 2001.

[11] B. Kargi. Interaction between the Economic Growth and the Construction Industry: A Time Series Analysis on Turkey (2000-2012), Emerging Markets Journal, Vol. 3, pp. 19-34, 2013. DOI:10.5195/emaj.2013.37.

[12] N. Saka, J. Lowe. An Assessment of Linkages between the Construction Sector and Other Sectors of the Nigerian Economy, The Construction, Building and Real Estate Research Conference of the Royal Institution of Chartered Surveyors held at Dauphine Université, Paris, 2-3 September, 2010.

[13] Central Bank of Nigeria (CBN). Modelling the Real Sector of the Nigerian Economy, Research Department, 2013. Online available from www.cbn.gov.ng.

[14] R. B. Isa, R. A. Jimoh, E. Achuenu. An Overview of The Contribution of Construction Sector to Sustainable Development in Nigeria, Net Journal of Business Management, Vol. 1, No. 1, pp. 1-6, 2013. 
[15] P. U. Okoye. Optimising the Capacity of Nigeria Construction Sector for Socio-economic Sustainability. British Journal of Applied Science \& Technology, Vol. 16, No. 6, pp. 1-16, 2016. DOI: 10.9734/BJAST/2016/26268.

[16] M. A. Yusuf. An Investigation into the Contribution of Construction Industry in Nation Gross Domestic Product (GDP), Proceedings of the Academic Conference on Agenda for Sub-Sahara Africa, University Of Abuja, Teaching Hospital, Conference Hall, Gwagwalada, Abuja FCT-Nigeria, Vol. 4, No. 1, 28th April, 2016.

[17] World Bank. Nigeria Economic Report, Document of the World Bank, 89630, 2014.

[18] Central Bank of Nigeria (CBN). CBN Statistical Bulletin 2009, 2010. Online available from https://www.cbn.gov.ng/OUT/2 010/PUBLICATIONS/STATISTICALBULLETINS/2009/P artC/PartC.html.

[19] National Bureau of Statistics (NBS). Revised 2010 and Estimates for Q1-Q4, 2011 Gross Domestic Product for Nigeria, 2012. Online available from www.nigeranstat.gov.n g.

[20] National Bureau of Statistics (NBS). Revised 2011 and Estimates for Q1-Q4, 2012 Gross Domestic Product for Nigeria, 2013. Online available from www.nigeranstat.gov.n g.

[21] National Bureau of Statistics (NBS). Revised and Final GDP Rebased Result by Output Approach, 2014b. Online available from www.nigeranstat.gov.ng.
[22] National Bureau of Statistics (NBS). Nigerian Gross Domestic Product Report, Quarter four 2014, Issue 4, 2015b. Online available from www.nigeranstat.gov.ng.

[23] National Bureau of Statistics (NBS). Nigerian Gross Domestic Product Report, Quarter four 2015, Issue 8, 2016a. Online available from www.nigeranstat.gov.ng.

[24] National Bureau of Statistics (NBS). Post GDP Rebasing Revision: 1981-2010, 2016b. Online available from www.nigeranstat.gov.ng.

[25] A. P. Field. Discovering statistics using SPSS, 2nd Edition, Sage, London, 2005.

[26] I. Erol, U. Unal. Role of Construction Sector in Economic Growth: New Evidence from Turkey, Munich Personal RePEc Archive, pp. 1-31, 2015. Online available from https://mpra.ub.uni-muenchen.de/68263/.

[27] C. N. Kwanga. Nigeria's Rebased 2013 GDP: Contending the Debate. IOSR Journal of Humanities and Social Science (IOSR-JHSS) Vol. 20, Issue 3, Ver. III, pp. 27-34, March, 2015.Online available from www.iosrjournals.org. DOI: $10.9790 / 0837-20332734$.

[28] A. M. Okun. Potential GNP: Its Measurement and Significance, American Statistical Association, Proceedings of the Business and Economics Statistics Section, pp. 98-104, 1962.

[29] E. S. Knotek II. How Useful is Okun's Law? Economic Review, Fourth Quarter, pp. 73-103, 2007. 